\title{
Angiomatoid Spitz Nevus
}

\author{
Oh-Eon Kwon, M.D., Bon-Seok Ku, M.D., Yeong-Kyu Lee, M.D., \\ Young-Hun Kim, M.D., Ki-Ho Kim, M.D. \\ Department of Dermatology, College of Medicine, Dong-A University, Busan, Korea
}

Spitz nevus is a variant of melanocytic nevus which is histopathologically defined as large spindle and/or epithelioid cells. Angiomatoid Spitz nevus is a rare histologic variant of desmoplastic Spitz nevus characterized by prominent vasculature. We present a case of angiomatoid Spitz nevus, celluar type, that has not been reported before. We provide another example to show the remarkable diversity of Spitz nevus.

(Ann Dermatol (Seoul) 20(1) 14 17, 2008)

Key Words: Angiomatoid spitz nevus, Desmoplastic spitz nevus, Spindle and/or epithelioid cells

\section{INTRODUCTION}

Angiomatoid Spitz nevus (SN) was first described by Diaz-Cascajo et $\mathrm{al}^{1}$. They described a distinct variant of desmoplastic SN having a prominent vasculature. Angiomatoid SN exhibits a spindle and/or epithelioid nevus placed among angiomatoid densely arranged small blood vessels lined by plump endothelial cells embedded in a collagenous stroma.

We report a case of a patient with a pigmented papule which is composed of many spindle and epithelioid cells confined to the dermis with prominent vascularity. This resembled an angiomatoid SN, but differed in its cellularity. Therefore, we suggest that this histologic variant should be highlighted as an angiomatoid SN, cellular type.

\section{CASE REPORT}

A 13-year-old boy presented with an 8-yearhistory of a $0.8 \times 0.8 \times 0.6 \mathrm{~cm}$ pink and slightly pigmented dome-shaped papule on the auricle of the right ear (Fig. 1). According to the boy's

Received August 29, 2007

Accepted for publication January 2, 2008

Reprint request to: Ki-Ho Kim, M.D., Department of Dermatology, Dong-A University Hospital, 1, Dongdaesindong 3-ga, Seo-gu, Busan 602-715, Korea. Tel: 82-51240-5435, Fax: 82-51-253-0787, E-mail: khkim@dau.ac.kr parents, the lesion was not present at birth and had increased in size since it first appeared.

Histopathologically, the lesion was dome-shaped and symmetrical with a wedge-shaped growth pattern. There was epidermal thinning with a partial epidermal collarette and tumor cells involving the full thickness of the dermis. Tumor nests were composed entirely of spindle and epithelioid cells containing abundant cytoplasm with varying amounts of melanin granules. No significant varia-

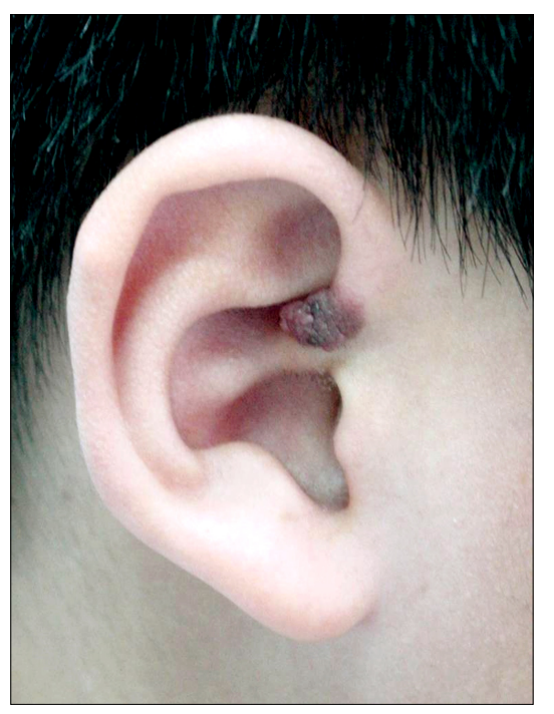

Fig. 1. A $0.8 \times 0.8 \times 0.6 \mathrm{~cm}$ pink, slightly pigmented dome-shaped papule on the auricle of the right ear. 

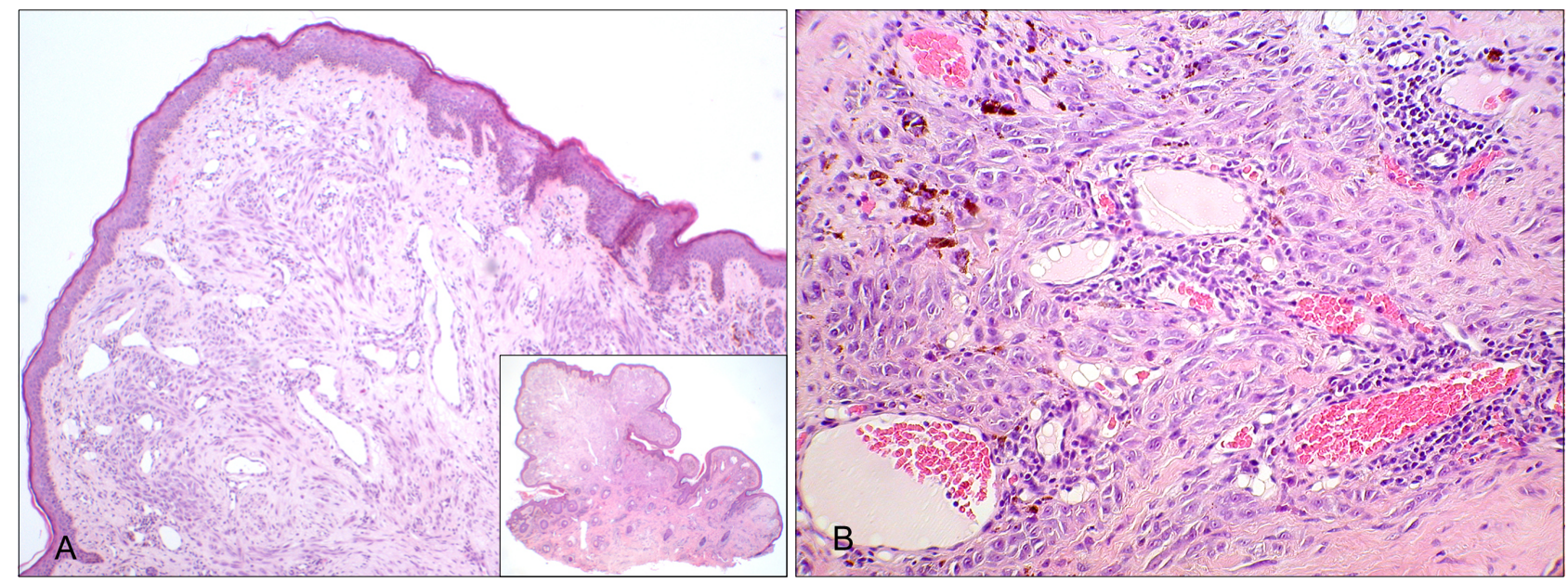

Fig. 2. There was epidermal thinning with a partial epidermal collarette and tumor cells involving the full thickness of the dermis without epidermal involvement (A-inset) $(\mathrm{H} \& \mathrm{E}$, original magnification $\times 10)$. Numerous small and large sized blood vessels are present in the upper and deep portion of the dermis (A) (H\&E, original magnification $\times 200$ ). Many spindle and epithelioid cells with abundant melanin granules are embedded in a desmoplastic stroma (B) $(\mathrm{H} \& E$, original magnification $\times 40)$. Small sized thick walled blood vessels are present in dermis $(\mathrm{C})(\mathrm{H} \& \mathrm{E}$, original magnification $\times 400$ ).

tion in size and shape of cells or nuclear hyperchromatism were observed. The fibrous stroma contained numerous small and large blood vessels lined by plump endothelial cells with monomorphous nuclei devoid of atypia. There were mixed thick and thin walled blood vessels (Fig. 2). Immunohistochemical staining demonstrated the tumor cells to mark strongly positive for S-100 protein within all of the nevus cells; HMB-45 staining was partially positive within upper dermal nests; Factor VIII and CD34 was positive within blood vessels (Fig. 3).

The nevus was removed by subtotal excision and the remaining lesion was treated by Alexandrite laser $(755 \mathrm{~nm})$ and SPTL1 pulsed dye laser $(585$ $\mathrm{nm})$. No recurrences or metastases were detected after 3 years of follow-up.

\section{DISCUSSION}

Spitz nevus refers to a large spectrum of nevi composed of spindle and/or epithelioid cells. Its basic architecture is similar to that of ordinary melanocytic nevi and may present as compound, junctional or intradermal lesions. Variants such as desmoplastic, hyalinizing, angiomatoid, pagetoid, pigmented spindle cell, and tubular epithelioid cell nevus have been reported and vary according to stroma or cellular composition.

Diaz-Cascajo et $\mathrm{al}^{1}$ first reported the entity now referred to as angiomatoid $\mathrm{SN}$ and this nevus is usually entirely intradermal. Neoplastic melanocytes show spindle and/or epithelioid features as in typical $\mathrm{SN}$. Angiomatoid SN shares some clinical and some histopathologic features with desmoplastic SN. Clinically, both types of lesions are frequently present as asymptomatic papules often located on the extremities of young adults. Histopathologically, both tumors show low cellular density, predominance of solitary melanocytes over nests, and abundance of fibrous stroma in the form of thick collagen bundles.

The SN often shows telangiectasia, which is more often seen in the upper part of the dermis ${ }^{2,3}$. Desmoplastic SN also shows more prominent vascular proliferation in the deep dermis ${ }^{4}$. Such histologic findings correspond to type $1 \mathrm{SN}$ among the four types of clinically classified SN and tend to be light-colored and soft 5 . They are frequently misdiagnosed as pyogenic granuloma or hemangioma. Such clinical misdiagnosis is suggested by a study of 200 SN cases noting that telangiectases occur much more frequently in children than in 

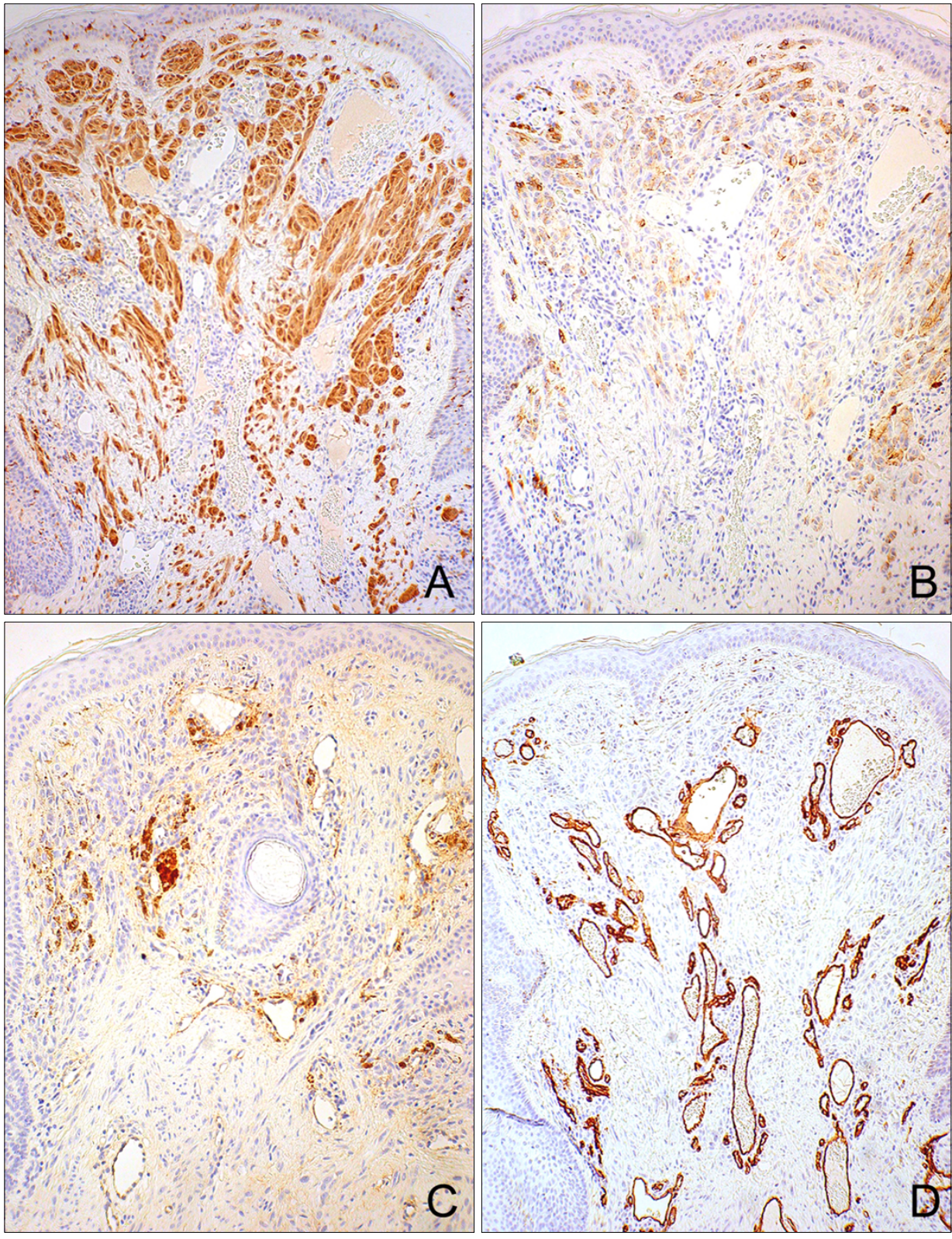

Fig. 3. Immunostaining for S-100 protein showed a positive reaction within the nevus cells (A), HMB-45 staining was partially positive within upper dermal nests (B), Factor VIII and CD34 was positive within blood vessels, respectively (C, D) (original magnification $\times 100$ ).

adults ${ }^{3}$. The recently reported SN cases ${ }^{6,7}$, which clinically look similar to a pyogenic granuloma, may be considered to be an angiomatoid SN accompanied by telangiectasia and an increased number of blood vessels. However, the blood vessels in angiomatoid SN are characteristically more numerous and smaller, rather than having thick vessel walls.

We found in our case: 1) spindle and epithelioid nevus cells 2) numerous thin and thick walled blood vessels distributed throughout the upper and deep dermis 3) fibrous stroma, which are regarded as features of angiomatoid SN. However, since the high cellularity of spindle and epithelioid cells differs from the earlier reports, we feel it appropriate to regard the current $\mathrm{SN}$ as angiomatoid, cellular type.

Regarding treatment of $\mathrm{SN}$, it has been suggested that because of the histologic overlap between SN and malignant melanomas, it may be advisable to remove the lesions by complete excision and to continue to observe the patient for recurrences. In 
our case, we treated by subtotal excision because the tumor was located over the auricular cartilage of the ear. In order to avoid underlying cartilage damage and eliminate the remaining lesion, pulsed dye and Alexandrite laser were further applied. No recurrences have been observed, after 3 years of follow-up.

Similar to desmoplastic SN, the histopathologic features of angiomatoid SN may present with various forms including fibrous stroma, prominent vasculature in the dermis, or a more dominant cellular type, as in our case. Therefore, angiomatoid $\mathrm{SN}$ could be considered as a variant of desmoplastic $\mathrm{SN}$ or it may represent another independent type of $\mathrm{SN}$.

\section{REFERENCES}

1. Diaz-Cascajo C, Borghi S, Weyers W. Angiomatoid Spitz nevus: a distinct variant of desmoplastic spitz nevus with prominent vasculature. Am J Dermatopathol 2000;22:135-139.

2. McKee PH, Calonje E, Granter SR. Spitz nevus, atypical spitz nevus and spitzoid melanoma. In: McKee PH, editor. Pathology of the skin. 3rd ed. London: Elsevier Mosby, 2005:1268-1275.

3. Paniago-Pereira C, Maize JC, Ackerman AB. Nevus of large spindle and/or epithelioid cells (spitz's nevus). Arch Dermatol 1978;14:1811-1823.

4. Tomizawa K. Desmoplastic spitz nevus showing vascular proliferation more prominently in the deep portion. Am J Dermatopathol 2002;24:184-185.

5. Casso EM, Grin-Jorgensen CM, Grant-Kels JM. Spitz nevi. J Am Acad Dermatol 1992;27:901-913.

6. Jose RM, Bennett A, Holmes J. Spitz naevi presenting as pyogenic granulomata. Br J Plast Surg 2005;58:1037-1039.

7. Jang HS, Cha JH, Oh CK, Kwon KS. Spitz naevus showing clinical features of both granuloma pyogenicum and pigmented naevus. Br J Dermatol 2001;145:349-350. 